\title{
AS EXPERIÊNCIAS DE VIDA E OS DESAFIOS DE HOMOSSEXUAIS BRASILEIROS: Uma revisão sistemática
}

DOI: $10.22289 / 2446-922 X . V 3 N 1 A 10$

\author{
Jane Alves do Carmo \\ Alex Garcia Cunha ${ }^{1}$
}

\section{RESUMO}

Este artigo tem como objetivo apresentar uma revisão sistemática de estudos realizados nos anos 2005 a 2016 visando mapear as experiências de homossexualidade narradas por homossexuais brasileiros, buscando compreender como a experiência homossexual tem sido vivenciada em nosso país. A revisão sistemática foi realizada a partir de artigos, dissertações e teses disponibilizados nas bases de dados Scielo, DOAJ, Pepsic e BVS, sendo utilizado o descritor "experiência homossexual", em língua portuguesa. Foram selecionados apenas estudos empíricos realizados no território brasileiro. Os resultados foram apresentados em cinco categorias de experiências: na adolescência e no início da idade adulta, na envelhescência, no trabalho, na participação em paradas GLBTs, no âmbito da maternidade e paternidade e na escola. Numa perspectiva geral, os estudos revelaram que mesmo diante de algumas conquistas, os homossexuais ainda são discriminados, atacados, rotulados e sofrem preconceitos na sociedade. Os estudos mostram ainda que a homofobia e o heterossexismo não acontece somente pelos heterossexuais, mas com os próprios homossexuais. Observou-se ainda que além do paradoxo da "saída do armário", a igreja e a família foram consideradas as principais reforçadoras e promotoras de ações homofóbicas.

Palavras-chave: experiência homossexual. homossexualidade. gays.

\section{ABSTRACT}

This article aims to present a systematic review of studies conducted in the years 2005 to 2016 aiming at mapping the experiences of homosexuality narrated by Brazilian homosexuals, seeking to understand how the homosexual experience has been experienced in our country. The systematic review was carried out from articles, dissertations and theses available on Scielo, DOAJ, Pepsic and BVS, using the descriptor "homosexual experience" in Portuguese. Only empirical studies carried out in Brazil were selected. Five categories were used to present the results: experiences in adolescence and early adulthood, in aging, at work, in participation in LGBT Pride Parades, in maternity and paternity, and in school. In a general perspective, studies have revealed that even in the face of some achievements,

\footnotetext{
${ }^{1}$ Endereço eletrônico de contato: alexgarciacunha@gmail.com

Recebido em 27/06/2017. Aprovado pelo Conselho Editorial e aceito para publicação em 01/07/2017.
}

Rev. Psicol Saúde e Debate. Jan., 2017:3(1):141-157. 
homosexuals are still discriminated against, attacked, labeled and suffer from prejudice in society. Studies also show that homophobia and heterosexualism do not happen only by heterosexuals, but by the homosexuals themselves. It was also observed that besides the paradox of "leaving the closet", the church and the family were considered the main promoters of homophobic actions.

Keywords: homosexual experience. homosexuality. Gays

\section{INTRODUÇÃO}

Sexualidade é uma das mais importantes e complexas dimensões da condição humana e sua compreensão envolve inúmeras variáveis, incluindo questões morais, políticas e ideológicas (1). Nesse contexto, a literatura registra a homossexualidade como sendo tão antiga quanto a própria humanidade, sendo praticada com naturalidade em civilizações antigas: ela estava presente tanto na Grécia quanto no Império Romano (2).

Naquela época, a pederastia era aceita com mais naturalidade, sendo inserida aos jovens rapazes como prática necessária para sua educação e desenvolvimento de sua masculinidade. Assim, quando se tornavam adolescentes, os meninos eram encaminhados aos cuidados de homens mais velhos para serem preparados para a vida pública (3). Era natural um homem mais velho se relacionar sexualmente com outro mais jovem, como parte da educação e formação dos jovens. Geralmente entre 12 e 18 anos, o jovem, por livre espontaneidade, relacionava-se com um homem mais velho, no papel de passivo, com a aprovação dos próprios pais (3). Por volta dos 25 anos, ao tornar-se homem, assumia seu papel de ativo, ou heterossexual. Os adolescentes pertencentes às famílias nobres se sentiam honrados ao serem escolhidos por estes homens mais velhos considerados sábios e guerreiros, que deles recebiam conhecimentos; estes jovens eram chamados de "efebos" (3).

No entanto, a homossexualidade passou a ser vista como uma situação problemática após o discurso médico-psiquiátrico, a partir do século XIX, que passou a denominá-la de anormalidade ou patologia (4). Com isso, foram aparecendo diversos outros discursos, como o médico-científico, o religioso etc., na busca de algo que identificasse suas causas e até mesmo legitimassem essa condição de ser, ou existir. O homoerótico era visto pela psiquiatria naquele tempo como algo 
perverso, um "homem-invertido" (1). Ademais, os homoafetivos eram rotulados de delinquentes, sendo vistos como um atentado à moral da sociedade, à semelhança de prostitutas, homicidas, doentes mentais e criminosos (5).

Com isso, durante décadas, cientificamente a homossexualidade foi considerada uma doença mental e os gays eram submetidos a diversos tratamentos absurdos, como hipnose, castração, terapias reparativas, choques elétricos, lobotomia etc. Essas práticas ainda ocorriam na Alemanha Ocidental em 1979 e na Dinamarca em 1981, onde cerca de 3,5 mil pessoas foram submetidas a lobotomia. Somente na década de 1990 a Organização Mundial da Saúde tirou a natureza patológica da homossexualidade (6). Ademais, criou-se o termo homossexualidade, em substituição a homossexualismo. Isso foi feito pelo jornalista austro-húngaro Karl-Maria Kertbeny, no final da década de 1860. Nas palavras de Silva Júnior (7),

Em 1975, foi inserido na Classificação Internacional das Doenças - CID, como sendo um transtorno sexual. Em 1985, a Organização Mundial de Saúde - OMS, publicou Circular, informando que o "homossexualismo" deixava de ser uma doença, passando a ser considerado um desajustamento comportamental. Mas foi em 1995, que o "homossexualismo" deixou de ser considerado um distúrbio psicossocial e consequentemente deixou de constar no CID, sendo substituído o sufixo "ismo" pelo sufixo "dade", que passou a significar "modo de ser.

Todavia, mesmo diante desses pequenos avanços, discrimina-se, ataca-se e rotula-se o homossexual, tanto que a maior parte das pessoas, quando se refere a um homossexual, se utiliza de expressões como "bicha", "gay", "viado", "biba", "boiola" e tantas outras, dependendo da cultura. Em alguns países, os homossexuais são perseguidos e até mesmo mortos em virtude de sua condição'. De acordo com Parker, antropólogo americano e estudioso dessa temática, o homossexual muitas vezes é visto como um objeto de constante ridículo e vergonha (8). Nesse sentido, se a homossexualidade fosse uma escolha, poderíamos afirmar

\footnotetext{
1 Veja o caso atual da Chechênia, por exemplo, em http://www.bbc.com/portuguese/internacional39603792. Acesso em 06/05/2017.
}

Rev. Psicol Saúde e Debate. Jan., 2017:3(1):141-157. 
que muitos homossexuais iriam optar por não serem homossexuais, evitando-se assim todas as agressões de natureza afetiva, emocional e física.

No âmbito dessa discussão, estudos têm sido feitos com homossexuais sobre suas trajetórias e experiências de vida no tocante à sua homossexualidade. Consideramos de maior destaque aqueles que dão voz ao homossexual, porque, conforme pontua Miccoli (9), "ao dar voz àquele que vivencia o processo, (...) tem-se uma visão desse processo muito diferente daquele que observa sem ter a experiência. (...) [A] compreensão daquilo que investigamos é ampliada quando aquele que vivencia é quem conta a história" (p. 208).

\subsection{OBJETIVOS}

Este artigo tem como objetivo apresentar uma revisão sistemática de estudos realizados nos últimos anos (2005 a 2016) visando mapear as experiências de homossexualidade narradas por homossexuais brasileiros, buscando compreender como a experiência homossexual tem sido vivenciada em nosso país.

\section{MÉTODO}

A revisão sistemática foi empreendida a partir de artigos, dissertações e teses disponibilizados entre 2005 e 2016 nas bases de dados Scielo, DOAJ, Pepsic e $B V S$, sendo utilizado o descritor "experiência homossexual" em língua portuguesa. Para a inclusão dos artigos, foram empregados os seguintes critérios: estudos empíricos realizados no território brasileiro e publicados na íntegra que retrataram, por meio da voz de homossexuais, suas experiências acerca da homossexualidade. Foram excluídos artigos de revisão ou reflexão e aqueles que não apresentavam o resumo nas bases de dados. Nos casos em que a leitura do resumo não foi suficiente para estabelecer se o estudo seria incluído, este foi lido na íntegra para determinar sua elegibilidade.

\section{RESULTADOS E DISCUSSÃO}

Seguindo o descritor "experiência homossexual", a pesquisa resultou em um total de 69 estudos nas bases de dados citadas. Destes, 14 estudos para a revisão sistemática foram selecionados, considerando-se os critérios de inclusão e exclusão Rev. Psicol Saúde e Debate. Jan., 2017:3(1):141-157. 
delineados acima. A partir daí, criaram-se seis categorias para agrupar os resultados sob um ponto de vista coerente, apresentando as experiências e trajetórias vivenciadas por homossexuais brasileiros. Apresentamos a seguir as experiências reveladas nos estudos encontrados.

\subsection{Experiências na adolescência e no início da idade adulta}

Cinco estudos focando as experiências de adolescentes e jovens homossexuais foram encontrados. No primeiro, Santos e Freitas (10) discutem dois casos de homossexualidade, um masculino e outro feminino, no início da adolescência, considerando-se a função paterna. Observou-se uma desestruturação familiar e a falta de orientação sexual ao adolescente. No primeiro caso, o adolescente, ao presenciar a mãe trair o pai dele, desenvolve uma relação afetiva positiva em relação à figura masculina e aversiva em relação à figura feminina. No segundo, a adolescente, ao presenciar as traições do pai em relação à mãe, desenvolve uma relação afetiva positiva em relação à figura feminina e repulsiva em relação à figura masculina.

Por sua vez, o estudo realizado por Silva Filho e Rodrigues (11), realizado no norte do Brasil, mostra que entre revelar e esconder, alguns adolescentes e jovens procuram formas de privacidade dentro do mundo homofóbico, criando uma linguagem apropriada, o "bajubá". Já Silva, Paiva e Parker (12) apresentam em seu estudo um grupo de adolescentes e jovens de variadas crenças religiosas que veem o homoerotismo como doença e pecado, mas respeitam e aceitam a orientação sexual de cada um, como um gesto de acolhimento e amor; alegam não concordar com a homossexualidade, mas revelam amar os homossexuais.

Soliva e Junior (13) revelam as experiências de adolescentes e jovens homossexuais que, ao se revelarem, foram agredidos ou violentados fisicamente pela própria família. Segundo seus relatos, fizeram uma associação da violência sofrida aos problemas enfrentados, entre eles, a violência psicológica e a baixa autoestima, que os conduziam a vulnerabilidades perigosas, como uso de drogas, sexo sem preservativos e até tentativas de suicídio. Observou-se que a experiência 
da homossexualidade é vista, aceita e vivenciada de diversas formas, dependendo dos costumes e tradições da sociedade em que o homossexual está inserido.

Por fim, os estudos de Taquette, Vilhena, Santos e Barros (14) e Taquette e Rodrigues (15) retratam as experiências de adolescentes com os sistemas de saúde. De acordo com esses estudos, nos atendimentos em serviços de saúde pública há um grande despreparo por parte dos profissionais que atendem os adolescentes homossexuais, principalmente no que se refere à orientação quanto a sexualidade e a prevenção e proteção de doenças sexualmente transmissíveis. Os resultados destacam a necessidade de profissionais mais instruídos e empenhados a dar mais esclarecimentos e orientações a respeito do desenvolvimento da sexualidade, em que se busque maior compreensão de significados do fenômeno, visando diminuir a vulnerabilidade e melhorar a saúde física, sexual e psicológica dos adolescentes homossexuais nos serviços de saúde e institucionais.

De acordo com essas pesquisas, geralmente os adolescentes encontram muita dificuldade em procurar a atenção primária para consulta médica. E quando isso acontece, os médicos deveriam estar atentos e aproveitar a oportunidade para criarem um vínculo a fim de que possam explorar mais a vida sexual dos adolescentes. No estudo de Taquette e Rodrigues (15), a maior parte dos entrevistados relatam que já fizeram ou fazem uso de álcool e drogas, não usam preservativos e ainda alguns sofreram violência em casa. Certamente ao procurarem o atendimento de saúde não vão falar sobre sua sexualidade se não lhe perguntarem ou lhe derem uma oportunidade para falar sobre tal.

Taquette, Vilhena, Santos e Barros (14) destacam que o adolescente raramente busca atendimento médico em função de problemas relacionados às suas experiências homossexuais. De acordo com os autores, às vezes, numa primeira consulta, o adolescente não consegue se abrir e fazer confidências, mas é importante que perceba que há espaço para tal. Por fim, os autores asseveram a importância de os médicos conhecerem a sexualidade de seus pacientes a fim de prevenir os riscos a que estão expostos gays, lésbicas e bissexuais. Revelam ainda que os médicos, em geral, partem do princípio que todos os seus pacientes são heterossexuais; assim, os adolescentes homossexuais acabam por não ter o devido 
espaço para receberem informações importantes acerca de sua sexualidade, para prevenirem doenças e terem uma melhor qualidade de vida.

\subsection{Experiências na envelhescência}

O estudo de Cardoso e Chaves (16), conduzido numa cidade do interior do estado do Pará, localizada na ilha de Marajó, na Amazônia Brasileira, revelou o rompimento de regras e normas estabelecidas pela sociedade, de que o idoso, inclusive o homossexual, estaria destinado, na velhice, a recolher o corpo e viver solitário e abandonado, fazendo uso de sua aposentadoria e conformando com as determinações médico-gerontológicas.

A pesquisa revelou, por meio de relatos coletados com quatro amigos homossexuais em processo de envelhescência, que, independente de idade, seus desejos e práticas sexuais estavam sempre renovados, mantendo uma vida ativa nesse sentido, vivenciando normalmente suas experiências homoafetivas. O estudo se deu por meio de uma pesquisa de campo /doutorado do programa de pósgraduação em antropologia da Universidade Federal do Pará (PPGA/UFPA). O método utilizado na pesquisa foi a observação participante, por meio de diálogo e várias visitas aos participantes, que não se opuseram em ser interlocutores relatando suas vidas sexuais. Cardoso e Chaves (16), concluíram que na envelhescência tudo dependerá de como cada indivíduo encara a vida, pois mesmo perdendo algumas agilidades, o corpo perdendo a flacidez, habilidades e coordenação motora diminuída, muitos homossexuais como estes levam uma vida ativa e animada.

\subsection{Experiências no trabalho}

O estudo de Souza e Pereira (17), foi realizado através de uma pesquisa qualitativa com análise de discursos de oito trabalhadores que se declararam homossexuais, funcionários em empresa pública de economia mista, todos com ligação ao setor de serviço. A idade variou de 40 a 53 anos, entre oito a 30 anos de 
tempo de trabalho, sendo a maior parte de 20 a 30 anos de trabalho na empresa. Os dados foram coletados por meio de entrevista semiestruturada e gravada.

O estudo revelou que dentro deste ambiente organizacional havia grande homofobia pelos próprios homossexuais. O estudo revelou ainda que a homofobia e o heterossexismo não acontece somente pelos heterossexuais, mas com os próprios homossexuais, que têm aversão ao comportamento efeminado de seus pares. São falas dos participantes dessa pesquisa:

[...] quanto mais efeminado é o homossexual, mais vítima de preconceito ele é. Então assim, na minha opinião, o preconceito contra o homossexual aumenta na medida que ele se torna mais efeminado. (Participante)

A demonstração exagerada do que você é, da sua condição sexual. Acho que não no trabalho só. Mas em qualquer lugar da vida, você não tem que tá levantando bandeira e eu realmente odeio "veadinhos", odeio "bichinhas", odeio aquelas coisinhas que querem mostrar a mamãe: eu sou "veado" e daí? Sabe, que já tem cara de "veado", se veste como "veado", fala como "veado" e ainda quer mostrar mais ainda que são "veados". Isso realmente até eu discrimino. (Participante)

Os participantes destacam que quem age como heterossexual é visto como normal, enquanto que os que comportam efeminadamente são rejeitados, colocando-os inferiores dentro da escala social estabelecida. Assim, muitos buscam se vestir e comportar de acordo com os padrões heterossexistas a fim de se evitar tal situação.

\subsection{Experiências de participação nas paradas GLBTs}

Estudo realizado por Costa, Machado e Prado (18) apresenta as experiências vivenciadas por um grupo de 421 GBLTs - homens, mulheres e transgêneros -, objetivando mostrar o dilema da homossexualidade vivenciado no tocante à participação política entre o individual e o coletivo. 
Os autores fizeram um procedimento de cruzamento qualitativo e quantitativo de dados coletados por meio de questionário aplicado na 8a Parada GBLT de Belo Horizonte. O questionário continha 34 questões visando conhecer as representações que os GLBTs tinham de algumas reivindicações do movimento. Pra a aplicação do questionário, a metodologia baseou-se na amostragem de três cotas, sendo homens, mulheres e transgênicos, avaliados conforme a escolaridade e faixa etária.

O objetivo foi compreender os fatores psicossociais, estruturais e conjunturais que apresentavam o impedimento de participação política dos GLBTs nesse movimento social, mais precisamente em Belo Horizonte. Costa, Machado e Prado (18) também realizaram uma entrevista qualitativa semiestruturada com seis participantes, que foram gravadas e transcritas. $O$ estudo revelou que a promoção individual de uma atuação política deixa transparecer o medo da homossexualidade se tornar visível, bem diferente da atuação coletiva que atua sem mostrar quem realmente é. Esse cruzamento e as entrevistas realizadas mostraram que, além do paradoxo da "saída do armário", a igreja e a família foram consideradas as principais reforçadoras e promotoras de ações homofóbicas, vistas como adversárias na luta pela conquista e garantia de direitos para os GLBTs.

\subsection{Experiências no âmbito da maternidade e paternidade}

Encontraram-se quatro estudos focando os obstáculos enfrentados na questão da maternidade e paternidade homoafetiva. Martinez e Barbierei (19) mostram a frustação no papel materno dentro de uma relação homoafetiva feminina. Ou seja, conforme a tradição mais aceita pela sociedade, numa família os pais se constituem em mulher e homem. Todavia, hoje um casal homossexual tanto masculino quanto feminino podem se casar e adotar crianças. O estudo mostra um casal feminino que está junto há mais ou menos 20 anos. Ambas trabalhavam no mesmo local e tiveram um filho, sendo uma delas a mãe biológica.

A mãe biológica trabalha durante o dia e estuda à noite e na entrevista não escondeu que mantinha relações extraconjugais homo e heterossexuais. Num destes relacionamentos, engravidou-se e sua parceira declarou que assumiu sua homossexualidade e fidelidade no relacionamento. Houve rejeição da gravidez por 
parte da mãe biológica, que, durante a entrevista, falou ter sido rejeitada por sua mãe na gravidez e que a união de seus pais era muito conturbada. Mesmo depois do parto, a rejeição da criança continuou e seu filho foi cuidado pela sua companheira, que se considerava o pai da criança, desempenhando todos cuidados de mãe, como dar banho, levar ao médico, cuidar da educação. Ou seja, ficou nítido o desempenho maternal ocorrido pela parceira e não pela mãe biológica.

Corrêa (20) mostra o caminho árduo que as lésbicas têm a percorrer para realizar o desejo da maternidade: enfrentam os preconceitos homoafetivos, a visão religiosa diante da situação, a falta da presença paterna no âmbito familiar e a questão da visão da família tradicional. Como resultado dessa pesquisa, mais uma vez se tem a percepção de que a orientação sexual do casal homoafetivo não interfere no desenvolvimento e orientação sexual da criança.

Nesse estudo, entrevistaram-se 12 lésbicas tanto solteiras como em relacionamentos, com filhos ou em planejamento de tê-los. Não foi fácil o acesso a essas participantes, a autora recorreu a uma ONG e sem êxito entrou em contatos de indicações de amigas da faculdade, buscou na internet e também participantes da Parada de Lésbicas de São Paulo, realizada em junho de 2009. Das 12 entrevistadas na época, três estavam solteiras, duas delas engravidaram por fertilização in vitro, a outra foi com um amigo gay. Das nove que estavam em relacionamento, dois casais conseguiram pela reprodução assistida, as demais estavam tentando ou planejando. Para engravidar por produção assistida passaram por vários processos, como a decisão de qual das duas seria a mãe biológica, a escolha do procedimento que foi a inseminação, a escolha do doador anônimo/conhecido.

O estudo mostra ainda que lésbicas passam por situações difíceis ao procurarem escola par o filho, mesmo fazendo uma boa escolha de escola: não podem evitar desconforto e descriminação social ao filho. Essa descriminação ocorria por parte de outros pais e até mesmo por coleguinhas. Relataram passar pelo transtorno de a mãe biológica estar viajando e precisar internar a criança no hospital e ser barrada pela direção que exigia um responsável familiar, uma vez que no registro constava somente o nome da mãe biológica. 
As lésbicas relatam indignação por terem que pagar tão caro para conseguir registrar a criança em seus nomes, enquanto que é tão simples e gratuito para os heterossexuais. Com isso, vivem numa total insegurança esperando que possam mudar as leis brasileiras e facilitar suas vidas. No estudo, as lésbicas entrevistadas expressam claramente o estresse gerado por terem de estar todo tempo provando que são capazes de educar seus filhos como qualquer outra família, sem trazer nenhuma consequência negativa para desenvolvimento psicológico da criança, sendo estes argumentos constante de pessoas contra as famílias homoparentais. Conclui-se ser notório que para optar pela maternidade em uma sociedade heteronormativa, é necessário ter fôlego e persistência, pois o caminho a percorrer é longo e difícil.

Por sua vez, Amazonas, Veríssimo e Lourenço (21) apresentam um estudo sobre a experiência de três homens assumidamente gays em contextos diferentes. Esses homens realizaram o desejo da paternidade por meio da adoção de crianças. Os autores relataram como se deu a construção do sentimento de paternidade por meio da adoção. Os dados, coletados por meio de entrevistas, mostram que desejar ter um filho, ser capaz de amá-lo e se responsabilizar por ele não está diretamente relacionada à orientação sexual, pois a construção do sentimento de paternidade tanto pode acontecer no contato diário com a criança, quanto desde o primeiro momento em que a vê.

Segundo os autores, as estratégias utilizadas pelos participantes a fim de se tornarem pais variaram desde o enfrentamento das dificuldades, assumindo sua orientação afetivo-sexual, ao ocultamento desta, a fim de atenuar conflitos na vida familiar e social. O estudo mostra que os participantes são próximos aos seus filhos, sabendo a importância da revelação da adoção, contando a história de suas vidas e suas origens. De acordo com o estudo, eles mantêm um forte vínculo afetivo com seus filhos adotivos, não vendo na discriminação sexista empecilhos suficientes para atenuar o amor que cultivam na relação com eles.

Ainda envolvendo a questão da maternidade, Hauer e Guimarães (22) buscaram compreender como acontece o processo de elaboração e aceitação da mãe diante da homossexualidade de suas filhas. O estudo mostra que esse 
processo é permeado de embates entre suas concepções e o amor às filhas, o que gera culpabilização, busca de explicações. De acordo com os autores, "a ideia do que é ser homem ou mulher, a forma 'correta' de expressão da sexualidade, os planos futuros feitos em torno de uma provável relação heterossexual da filha" ( $p$. 649) são revistos, repensados, desconstruídos e reconstruídos. Concluem destacando a necessidade de se aumentar a discussão no tocante ao papel da mãe no processo de experiência da homossexualidade dos filhos, "pois ainda são muitos os estereótipos e preconceitos direcionados aos desviantes da norma" (p. 661).

\subsection{Experiências escolares}

Ferrari (23) fez um estudo através de uma carta que foi escrita por uma adolescente, estudante de escola pública, endereçada a uma professora de ciências. Trata-se de uma adolescente cheia de dúvidas, querendo conhecer mais sobre o lesbianismo. Ela relatou que tocou e foi tocada pelo sexo masculino, mas que em nenhum momento sentiu desejo ou prazer; pelo contrário, somente nojo. Revelou que sentia desejos pelo mesmo sexo, mesmo não tendo o conhecimento do ato sexual. Sofre com isso e relatou não querer mais ter tais desejos.

De acordo com o autor:

(...) a escrita da carta é, então, nessa perspectiva, algo que diz desta menina de uma forma mais particular e solitária, mas que é potente, na medida em que escapa a pura subjetividade, fazendo com que outros meninos e outras meninas possam dialogar, cruzar e atravessar essa experiência. (p. 104)

O estudioso questiona o tipo de sociedade em que estamos vivendo e como está sendo o relacionamento entre alunos, escolas e professores hoje diante da sexualidade. Acrescenta que essa carta não é um caso isolado, pois constantemente tem lido correspondências dessa espécie, advindas de alunos, professores e até diretores. Para o autor, desmistificar as imagens negativas da homossexualidade e construir imagens positivas é necessário. Para isso, as escolas e a formação docente é peça fundamental nesta política, segundo o pesquisador. 0 
papel do psicólogo escolar, nesse sentido, torna-se fundamental no sentido de acolher, ouvir e orientar os adolescentes, a comunidade escolar, e a família (24).

\section{CONSIDERAÇÕES FINAIS}

Embora aos olhos da psicologia contemporânea a homossexualidade seja tão natural quanto a heterossexualidade ou qualquer outra orientação sexual, assim como é natural ser destro ou canhoto, o que se observou neste estudo foi que a condenação que os homossexuais sofrem em seu meio é o que mais causa sofrimento e não a homossexualidade em si.

Em relação às experiências mapeadas neste artigo, pôde-se observar que o adolescente, ao se perceber homossexual, se vê desnorteado, sem saber lidar com a situação e muitos tentam se omitir em questão à sua orientação sexual, tentando em alguns casos se relacionar com o sexo oposto, ignorando seus desejos pelo mesmo sexo. Outros se envolvem com práticas não saudáveis, como o uso de drogas ou tentativas suicidas.

Quando se aceitam, o primeiro passo é se revelarem à família. Quando isso ocorre, alguns são até mesmo agredidos e violentados fisicamente ou expulsos de casa. As mães, quando descobrem a homossexualidade de seus filhos, primeiro entram em choque ou preconceito interior, uma confrontação, se culpam pela situação, buscam por explicações e vivem uma frustação materna e, por fim, aceitam a homossexualidade dos filhos encarando como normal ou obra do destino. Ainda no tocante aos adolescentes, constatou-se que não encontram o devido espaço nos atendimentos de saúde para falarem de sua sexualidade e receberem orientação e cuidados que Ihes são específicos, uma vez que os médicos muitas vezes partem do pressuposto que seus pacientes são heterossexuais e a questão da homossexualidade ainda é pouco enfocada nos atendimentos.

$\mathrm{Na}$ escola, percebeu-se a necessidade de essa instituição se mostrar acolhedora, formando melhor seus profissionais e oferecendo espaço para discussões acerca da sexualidade.

Já nas experiências vivenciadas no âmbito de trabalho, foi perceptível a homofobia advinda dos próprios homossexuais, demonstrando aversão aos Rev. Psicol Saúde e Debate. Jan., 2017:3(1):141-157. 
comportamentos efeminados. Notou-se, também, dificuldade de alguns homossexuais conseguirem uma vaga de trabalho no mercado.

Os estudos mostraram também as experiências de homossexuais que lutam pelos seus direitos civis, incluindo o casamento, a adoção de crianças e a política social. Nesse sentido, a maioria dos obstáculos enfrentados surge das próprias famílias e da igreja.

Evidenciou-se também que embora a paternidade ou maternidade do homossexual seja possível, constituindo-se pelo vínculo familiar de amor, respeito e valores, ainda são muitos os embates com a sociedade, que muitas vezes se mostra preconceituosa, não aceitando esse padrão familiar.

Por outro lado, percebeu-se que o homossexual pode ter uma envelhescência plena, vivenciando sua homossexualidade de modo saudável, na presença de companheiros de vida - namorados, por exemplo - e/ou amigos.

Em face do estudo apresentado, pode-se dizer que embora grandes avanços tenham sido alcançados em relação aos direitos e à aceitação da homossexualidade como algo natural, há ainda um caminho longo a se trilhar nessa direção. Dar voz aos homossexuais, buscar compreender suas experiências e trajetórias de vida, socializar tais experiências, discuti-las de maneira a suspender preconceitos e a buscar um entendimento e uma aceitação natural e humana dessa condição pode ser um passo importante. Na esfera acadêmica, sugere-se a realização de mais pesquisas nesse sentido, retratando a homossexualidade a partir da voz daqueles que a experienciam em sua existência.

\section{REFERÊNCIAS}

1 Ceccarelli PR, Franco S. Homossexualidade: verdades e mitos. Revista Bagoas. 2010; 05 (1): 119-129

2 Frazão $P$, Rosário $R$. O coming out de gays e lésbicas e as relações familiares. Psicológica. 2008;1:25-45. 
3 Dieter CT. As raízes históricas da homossexualidade, os avanços no campo jurídico e o prisma constitucional. Inst Bras Direito Família [Internet]. 2009;16. Disponível em: http://www.ibdfam.org.br/novosite/artigos/detalhe/812

4 Alexandre MES, Lima ED, Galvão LK de S. Homossexualidade e a Psicologia: revisitando a produção científica nacional. Rev Bras Psicol. 2014;2(1):132-47.

5 Nunan A. Homossexualidade: do preconceito aos padrões de consumo. Rio de Janeiro: Caravansarai; 2003.

6 Lima C de C. A história da homossexualidade e a luta pela dignidade [Internet]. Guia do estudante; 2012.2 Disponível em: http://guiadoestudante.abril.com.br/aventuras-historia/historia-homossexualidadeluta-pela-dignidade-718218.shtml

7 Silva Júnior, E.D. A possibilidade jurídica de adoção por casais homossexuais. 3rd ed. Juruá, editor. Curitiba; 2008.

8 Parker R. Abaixo do equador. Rio de Janeiro: Record; 2002.

9 Miccoli, LS. A Experiência na Lingüística Aplicada ao Ensino de Línguas Estrangeiras: levantamento, conceituação, referências e implicações para pesquisa. Rev bras Linguist apl [Internet]. 2005;207-48. Disponível em: /scielo.php?script=sci_arttext\&pid=\&lang=pt

10 Santos TC dos, Freitas RGA. A escuta analítica no espaço público. Rev Mal-estar e Subjetividade. 2005;5(2):246-60.

11 Silva Filho MR da, Rodrigues Cl. Digressões homossexuais notas antropológicas sobre coming out, Ethos LGBT e Bajubá em Belém. Rev NUFEN, Sér diálogos Divers [Internet]. 2012;4(1):44-58. Disponível em: http://pepsic.bvsalud.org/scielo.php?script=sci_arttext\&amp;pid=S217525912012000100005 
12 Silva CG, Paiva V, Parker R. Desafios Para a Promoção Da Saúde E De Direitos Sexuais. Interface Commun Heal Educ. 2013;17(44):103-17.

13 Soliva TB, Silva Junior JB da. Entre revelar e esconder: pais e filhos em face da descoberta da homossexualidade. Sex, salud soc (Rio J) [Internet]. 2014;(17):12448. http://www.scielo.br/scielo.php?script=sci_arttext\&amp\%5Cnpid=S198464872014000200124

14 Taquette SR, Vilhena MM, Santos ÚPP dos, Barros MMV de. Relatos de experiência homossexual em adolescentes masculinos. Cien Saude Colet [Internet]. 2005;10(2):399-407. Disponível http://www.scielo.br/scielo.php?script=sci_arttext\&pid=S1413-

$81232005000200018 \& \operatorname{lng}=$ pt\&nrm=iso\&tlng $=$ pt

15 Taquette SR, Rodrigues A de O. Experiências homossexuais de adolescentes: Considerações para 0 atendimento em saúde. Interface Commun Heal Educ. 2015;19(55):1181-91.

16 Cardoso W, Chaves E. Revista do NUFEN : phenomenology and interdiciplinary. Antropologia do envelhecimento gay - experiências e vivências cotidianas de um grupo de quatro amigos homossexuais em processo de envelhecência. 2014;6(1):43-86.

17 Souza EM de, Pereira SJN. (Re) produção do heterossexismo e da heteronormatividade nas relações de trabalho: a discriminação de homossexuais por homossexuais. Rev Adm Mackenzie. 2013;14(4):76-105.

18 Costa FA, Machado FV, Prado MAM. Participação política e experiência homossexual: Dilemas entre 0 indivíduo e o coletivo. Interam J Psychol. 2008;42(2):325-37.

19 Martinez ALM, Barbieri V. A experiência da maternidade em uma família homoafetiva feminina. Estud Psicol [Internet]. 2011;28(2):175-86. Disponível em: http://www.scielo.br/scielo.php?script=sci_arttext\&pid=S0103-166X2011000200005

20 Corrêa MEC. Duas mães: mulheres lésbicas e maternidade. [tese doutorado]. 2012. 
21 Amazonas MCLDA, Veríssimo HV, Lourenço GO. A adoção de crianças por gays. Psicol Soc [Internet]. 2013;25(3):631-41. Disponível em: http://www.scielo.br/scielo.php?script=sci_arttext\&pid=S0102$71822013000300017 \&$ Ing $=$ pt\&nrm=iso\&tIng=em

22 Hauer M, Guimarães RS. Mães, filh@s e homossexualidade: narrativas de aceitação. Temas em Psicol [Internet]. 2015;23(3):649-62. Disponível em: http://pepsic.bvsalud.org/pdf/tp/v23n3/v23n3a10.pdf

23 Ferrari Experiência homossexual no contexto escolar. Educar em Revista. 2014; 1(EE): 101-116.

24 Moreira IG, Oliveira RF dos S. a Importância Do Trabalho Do Psicólogo No Ambiente Escolar: Perspectivas Da Educação Na Atualidade. Psicol e Saúde em Debate [Internet]. 2016;2(EE):14-27. Disponível em: https://psicodebate.wordpress.com/edicoes-anteriores/volume-2-edicao-especial2016/a-importancia-do-trabalho-do-psicologo-no-ambiente-escolar-perspectivas-daeducacao-na-atualidade/ 